\title{
Reevaluation of Two Quantitative Trait Loci for Type II Resistance to Fusarium Head Blight in Wheat Germplasm PI 672538
}

\author{
X. Li, Z. P. Xiang, W. Q. Chen, Q. L. Huang, T. G. Liu, Q. Li, S. F. Zhong, M. Zhang, J. W. Guo, L. Lei, and P. G. Luo \\ First, second, fourth, sixth, seventh, eighth, ninth, and eleventh authors: State Key Laboratory of Plant Breeding and Genetics, Sichuan \\ Agricultural University, Chengdu, Sichuan 611130, China; first, third, fifth, and eleventh authors: State Key Laboratory for Biology of Plant \\ Diseases and Insect Pests, Institute of Plant Protection, Chinese Academy of Agricultural Sciences (CAAS), Beijing 100193, China; second \\ author: College of Food Science and Technology, Sichuan Tourism University, Chengdu, Sichuan 610100, China; sixth author: Department of \\ Biology and Chemistry, Chongqing Industry and Trade Polytechnic Institute, Fuling District of Chongqing 408000, China; and tenth author: \\ Department of Plant Pathology, Kansas State University, Manhattan 66506.
}

Accepted for publication 20 August 2016.

\begin{abstract}
Fusarium head blight (FHB), mainly caused by Fusarium graminearum, is a destructive disease in wheat. A population consisting of $229 \mathrm{~F}_{2}$ and $\mathrm{F}_{2: 3}$ plants derived from the cross PI $672538 \times$ L661 was used to evaluate the reactions to FHB. The FHB resistance data distribution in the $\mathrm{F}_{2}$ population indicates that some quantitative trait loci (QTLs) were controlling the FHB resistance in PI 672538. We further detected two major QTLs (Qfhs-2B, Qfhs-3B) from analysis of the resistance data and the PCRamplified results using WinQTLCart 2.5 software. $Q$ fhs- $2 B$, flanked by Xbarc55-2B and Xbarc1155-2B, explained more than $11.6 \%$ of the phenotypic variation of the percentage of diseased spikelets (PDS), and

Qfhs-3B, flanked by Xwmc54-3B and Xgwm566-3B, explained more than $10 \%$ of the PDS phenotypic variation in the $\mathrm{F}_{2: 3}$ population. In addition, $Q f h s-3 B$ was different from $F h b 1$ in terms of the pedigree, inheritance, resistance response, chromosomal location, and marker diagnosis. We also detected QTLs for other disease resistance indices, including the percentage of damaged kernels and 1,000-grain weight, in similar chromosomal regions. Therefore, the FHB resistance of PI 672538 was mainly controlled by two major QTLs, mapped on 2B (FhbL693a) and 3B (FhbL693b). PI 672538 could be a useful germplasm for improving wheat FHB resistance.
\end{abstract}

Fusarium head blight (FHB), caused mostly by Fusarium graminearum Schwabe (teleomorph Gibberella zeae (Schw.) Petch), is a destructive disease in wheat, especially in humid climates. This disease not only severely reduces yields due to shriveled seeds but also produces deoxynivalenol (DON), which is a danger to human health (Bai and Shaner 2004). Chemical control and agronomic measures are alternatives used to prevent this disease, but the development of FHB-resistant cultivars has been the most effective strategy for controlling the disease (Bai and Shaner 2004). Unfortunately, to date, wheat FHB resistance has not significantly improved due to the severe shortage of FHB-resistant germplasms, as well as the diversity of exhibited resistance and the complexity of genetic behavior (Liu et al. 2015; Mesterhazy 1995).

To develop resistant cultivars, the identification of new wheat FHB-resistant germplasms and the further utilization of new FHB resistance genes or quantitative trait loci (QTLs) are important tasks in breeding programs (Mesterhazy 1995). In the past, studies on the improvement of FHB resistance in hexaploid wheat have mainly focused on well-known resistant germplasms, such as Wangshuibai (Ma et al. 2008; Xiao et al. 2013; Xue et al. 2010, 2011; Zhou et al. 2004) and Sumai 3 (Cai and Bai 2014; Kolb et al. 2001; Waldron et al. 1999).

Corresponding authors: W. Q. Chen; E-mail address: mjy211@gmail.com, and P. G. Luo; E-mail address: lpglab@sicau.edu.cn

First and second authors contributed equally to this work.

*The $\boldsymbol{e}$-Xtra logo stands for "electronic extra" and indicates that seven supplementary figures and two supplementary tables are published online.

(c) 2017 The American Phytopathological Society
Genetic research has revealed that FHB resistance is usually a quantitative trait and controlled by multiple genes (Zhang et al. 2010; reviewed by Buerstmayr et al. 2009). To date, only seven major FHB resistance QTLs have been reported: Fhbl (Cuthbert et al. 2006; Liu et al. 2006), Fhb2 (Cuthbert et al. 2007), Fhb3 (Qi et al. 2008), Fhb4 (Xue et al. 2010), Fhb5 (Xue et al. 2011), Fhb6 (Cainong et al. 2015), and $F h b 7$ (Guo et al. 2015). In addition, numerous QTLs are reportedly associated with FHB resistance (reviewed by Buerstmayr et al. 2009). In fact, only few FHB resistance QTLs have been applied for wheat FHB resistance improvement due to their weak resistance, poor adaptation, and complex genetic backgrounds. Globally, wheat breeding heavily relies on the FHB resistance QTLs from Sumai 3 and its derivatives (Rudd et al. 2001). Therefore, it is very important to identify new resistance sources in wheat breeding programs.

Alien gene transfer is an important means of developing new resistant germplasms and increasing the genetic diversity of wheat FHB resistance. Of the seven permanently designated $F h b$ loci, three loci were transferred from wild relatives: Fhb3 from Leymus racemosus (Qi et al. 2008), Fhb6 from Elymus tsukushiensis (Cainong et al. 2015), and Fhb7 from Thinopyrum ponticum (Guo et al. 2015). Thinopyrum intermedium (Host) (Barkworth and D. R. Dewey) $\left(2 \mathrm{n}=6 \mathrm{x}=42 ; J^{\prime} J^{s} \mathrm{~s} S S\right)$ (syn. Elytrigia intermedia (Host) Nevski) is a useful source of resistance to FHB (Fedak and Han 2005; Liu et al. 2015), as well as against stripe rust and powdery mildew (Huang et al. 2014; Liu et al. 2013; Luo et al. 2009a, b; Shen et al. 2015).

The line L693 (Reg. No. GP-972, PI 672538) derived from the wild cross between common wheat and Thinopyrum intermedium (Liu et al. 2015) exhibits strong FHB resistance, which has been repeatedly evaluated by point- and spray-inoculation in multiple years and locations (Liu et al. 2015; Yang et al. 2016). This line also shows high resistance to stripe rust (Huang et al. 2014; Luo et al. 
2009a; Li et al. 2015) and powdery mildew (Luo et al. 2009b; Ma et al. 2015). Genomic in situ hybridization demonstrated the absence of alien chromosomal fragments in PI 672538 (Li et al. 2015). Moreover, PI 672538 has suitable agronomic and morphological traits (Liu et al. 2015). All data imply that PI 672538 had genes that were resistant to multiple diseases, especially FHB resistance. Therefore, characterizing the genetic behavior of FHB resistance and mapping the resistance QTLs in this line are valuable to wheat breeding.

To identify the genes affecting FHB resistance as quantitative traits, we first map the QTLs affecting the trait using early segregating populations, such as the $\mathrm{F}_{2}$ and $\mathrm{F}_{2: 3}$ populations (TamburicIlincic et al. 2002; Zhang et al. 2010). Next, we focus on each QTL region and further narrow the genomic intervals that carry the gene or genes affecting this resistance with a secondary mapping population. For example, the chromosomal intervals of $F h b 2$ (Cuthbert et al. 2007), Fhb4 (Xue et al. 2010), Fhb5 (Xue et al. 2010), and Fhb7 (Guo et al. 2015) were narrowed by recombinant inbred lines (RILs). Additionally, the chromosomal intervals of $F h b 1$ (Cuthbert et al. 2006), Fhb4 (Xue et al. 2010) and Fhb5 (Xue et al. 2010) were also narrowed by near isogenic lines (NILs), while some FHB resistance QTLs were narrowed by doubled haploid (DH) lines (Somers et al. 2006). Finally, we can pinpoint and clone the genes by chromosome walking or homogenous cloning. The early generation mapping populations are critical to the study of the uncertain genetic components in novel FHB resistance germplasm. First, the primary mapping $\mathrm{F}_{2}$ and $\mathrm{F}_{2: 3}$ populations play a key role in elucidating how many genes control FHB resistance and how the genes interact to cause resistance. Second, the primary mapping $\mathrm{F}_{2}$ and $\mathrm{F}_{2: 3}$ populations are essential in determining the original chromosomal locations of the FHB resistance QTLs, although the genetic mapping of the resistance QTLs with these populations has large confidence intervals due to the limitation of population size and marker density (Xue et al. 2010). Third, using the $F_{2}$ and $F_{2: 3}$ populations shortens the time required to construct the RIL population, which is useful for narrowing down the gene mapping on a finer scale. Moreover, a recent study suggested that $F_{2}$ populations could be effective indicators of the expression levels of FHB resistance QTLs prior to the secondary mapping population (Dvorjak 2014).

To accelerate the application of wheat resistance germplasm PI 672538 in wheat breeding, the objectives of this research were to study the inheritance of FHB resistance in PI 672538 and to construct a genetic map of the genes with simple sequence repeat (SSR) markers to determine the chromosomal locations of the genes. We also screened some closely linked markers to aid the molecular marker-assisted selection of FHB resistance.

\section{MATERIALS AND METHODS}

Plant materials. A total of $229 \mathrm{~F}_{2}$ plants from the cross $\mathrm{L} 661 \times$ PI 672538 and the corresponding $\mathrm{F}_{2: 3}$ families were used to map the QTLs. The wheat line PI 672538 was resistant to FHB (Liu et al. 2015; Zhang et al. 2011), whereas L661 was susceptible to FHB. The parents PI 672538 and L661 are sister lines with similar genetic backgrounds (Huang et al. 2014; Li et al. 2015) and were used to study the inheritance of FHB resistance. In addition, Chinese Spring nulli-tetrasomic (NT) lines were used to identify the chromosomal location of the resistance QTLs and the linked markers.

Evaluation of the reaction to FHB. The parental lines L661 and PI 672538 and the $229 \mathrm{~F}_{2}$ plants were grown spaced out individually in Ya' an (lat. $29^{\circ} 59^{\prime} \mathrm{N}$, long. $102^{\circ} 58^{\prime} \mathrm{E}$ ) in 2011 . The L661 and PI 672538 lines and $229 \mathrm{~F}_{2: 3}$ plants were grown in three locations, Ya' an (lat. 29 $59^{\prime} \mathrm{N}$, long. $102^{\circ} 58^{\prime} \mathrm{E}$ ), Qionglai (lat. $30^{\circ} 24^{\prime} \mathrm{N}$, long. $103^{\circ} 32^{\prime} \mathrm{E}$ ), and Wenjiang (lat. $30^{\circ} 43^{\prime} \mathrm{N}$, long. $103^{\circ} 52^{\prime} \mathrm{E}$ ), to evaluate the resistance to FHB in field trials in 2012. A completely random block design was used in every replication at each location. Each plot consisted of 3-m long rows, and the space between rows was $0.25 \mathrm{~m}$ with $0.15 \mathrm{~m}$ of plant space. To determine FHB resistance, $5 \mu \mathrm{l}$ of a macroconidial suspension (200 macroconidia per $\mu$ l) of the spore-derived isolate of $F$. graminearum No. 4 (provided by Z. Ma at Nanjing Agricultural University, Nanjing, Jiangsu Province, China) was injected into two opposite florets in a spikelet at early anthesis; four spikes of each $\mathrm{F}_{2}$ individual were inoculated in 2011, and the phenotype of the given $F_{2}$ plant is presented as the average of the four spikes. For each $\mathrm{F}_{2: 3}$ population in 2012, 10 plants were selected at each location, and three spikes of each plant were inoculated. The average of three locations represents the phenotypic value of the corresponding $\mathrm{F}_{2: 3}$ plant for mapping.

The inoculated spikes were covered with plastic bags for 3 days to maintain the relative humidity. The percentage of visibly diseased spikelets (PDS), including the inoculated spikelets, was recorded at 21 days after inoculation. At the maturity stage, the inoculated spikes were carefully harvested by hand and then dried at $35^{\circ} \mathrm{C}$. The number of kernels per spike and the number of damaged kernels were counted after threshing, and the total grain weight per spikes was evaluated. The data were used to calculate the percentage of damaged kernels (PDK) and the 1,000-grain weight (KGW).

Molecular marker screening. Genomic DNA was extracted from 5-week-old seedling leaves using the CTAB method

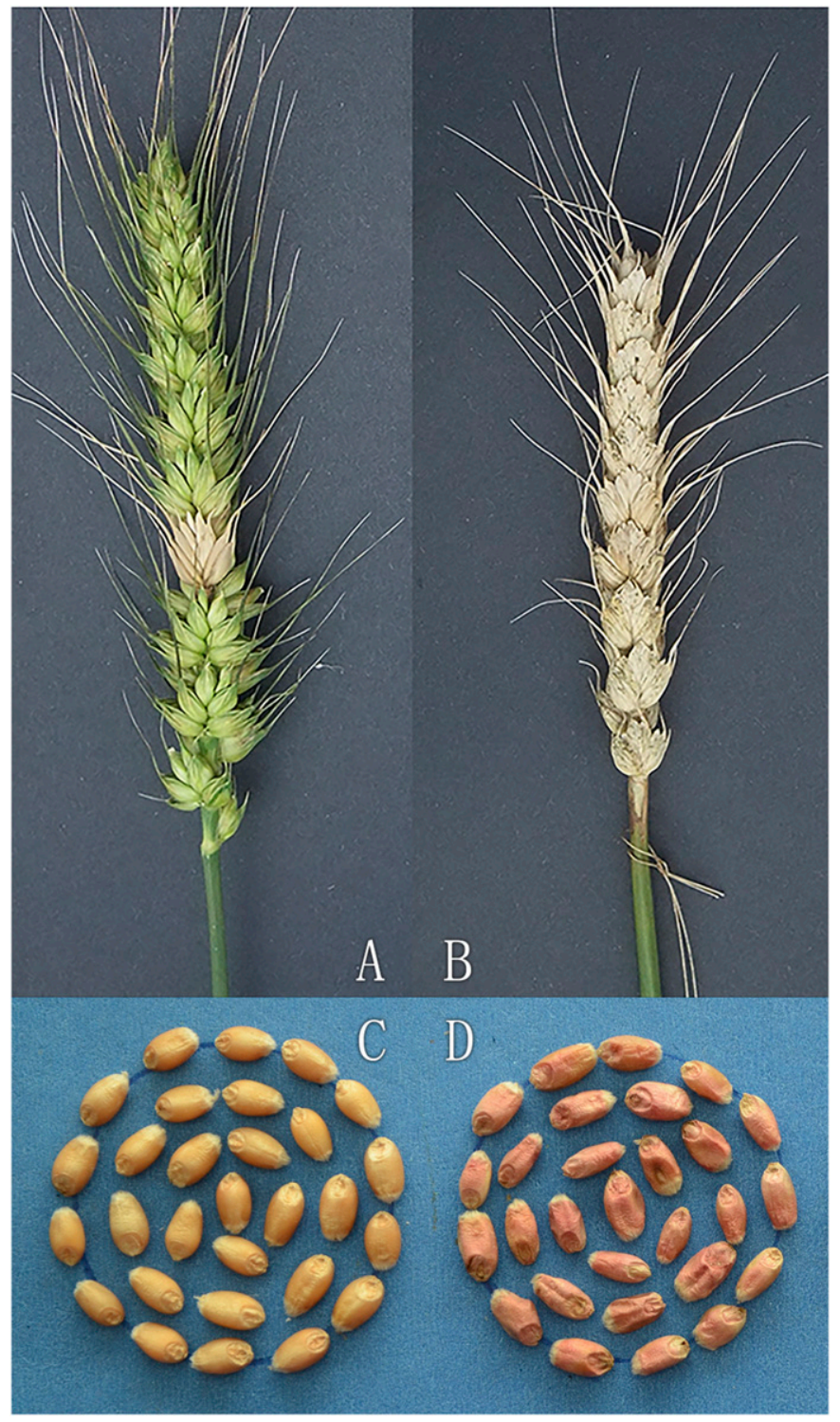

Fig. 1. Wheat reaction to Fusarium graminearum A, PI 672538 spike, B, L661 spike, C, PI672538 seed, and D, L661 seed. The photos of the spikes were taken 21 days after $F$. graminearum inoculation. 
previously described (Tai and Tanksley 1990). Forty-one polymorphic primers out of 781 microsatellites (from the gwm and wmc series) between L661 and PI 672538 (Huang et al. 2014) were directly applied to screen the whole $\mathrm{F}_{2: 3}$ mapping population. PCR amplification was performed according to a previously described method with minor modifications (Röder et al. 1998a, b). Each PCR mixture contained each SSR primer at a concentration of 200 nmol/liter, $0.2 \mathrm{mmol} /$ liter dNTPs, $1.5 \mathrm{mmol} /$ liter $\mathrm{MgCl}_{2}, 1$ unit of Taq polymerase, and $50 \mathrm{ng}$ of template DNA. PCR was performed following a previously described program (Luo et al. 2008). Each PCR product was mixed with $3 \mu$ l of loading buffer $(98 \%$ formamide, $10 \mathrm{mM}$ EDTA [pH 8.0], 0.25\% bromophenol blue, and $0.25 \mathrm{mg} / \mathrm{ml}$ xylene cyanol), denatured at $95^{\circ} \mathrm{C}$ for $5 \mathrm{~min}$, and chilled on ice. Subsequently, a $6-\mu \mathrm{l}$ aliquot of each sample was loaded onto a $6 \%$ polyacrylamide gel (19:1 acrylamide-bisacrylamide) with $8 \mathrm{M}$ urea and $1 \times \mathrm{TBE}(90 \mathrm{mM}$ tris-borate $[\mathrm{pH}$ 8.3], $2 \mathrm{mM}$ EDTA) prior to separation at $80 \mathrm{~W}$ for approximately $1.5 \mathrm{~h}$ and visualization by silver staining (Bassam et al. 1991).

Based on the original linkage analysis, we determined that two primers, $X w m c 441-2 B$ and $X g w m 566-3 B$, out of the 30 polymorphic primers from the $g w m$ and $w m c$ series (Huang et al. 2014) were linked with the FHB resistance QTLs in PI 672538 to some degree. Therefore, to verify the linkage relationship between the FHB resistance QTLs and markers, we further employed the other microsatellite primers, including the gwm (Röder et al. 1998b), wmc (Gupta et al. 2002; Somers et al. 2004), barc (Song et al. 2002), gpw (Sourdille et al. 2004), cfd (Guyomarc'h et al. 2002), cnl (Ma et al. 1996), mag (Xue et al. 2008), and psp (Bryan et al. 1997; Stephenson et al. 1998) series and the EST primer on the 2B and 3B chromosome, in PCR amplification. Nineteen published SSR primers on the $3 \mathrm{~B}$ chromosome were linked with the FHB resistance QTLs, and 14 published SSR primers and 1 published EST primer, BF478477 (Shen et al. 2015), on the 2B chromosome were also linked with the FHB resistance QTLs in PI 672538. After linkage analysis, we further saturated 2B by developing 40 new SSR primers according to the contig sequences carrying the markers that mapped to chromosome $2 \mathrm{~B}$ using the previously described methods (Shen et al. 2015; Supplementary Table S1).

Statistical analysis. Significant differences among the averages of the populations L661 and PI 672538 were determined by independent sample $t$ test using SPSS 19 (IBM SPSS Statistics for Windows, Version 19.0. IBM Corp., Armonk, NY), and the correlation analysis was determined with the same software using a bivariate method.

Linkage map construction and QTL analysis. The phenotype data were first quality controlled using QTmodel software (Yang et al. 2007) at a $t$ value threshold of 3.0. The genetic map was constructed with JoinMap 4.0 (Van Ooijen 2006) using the regression mapping algorithm and Kosambi (1943) mapping function. The logarithm of an LOD value of 3.0 was set as the threshold for grouping. The markers associated with FHB resistance were detected by simple regression analysis using SPSS software. The QTL analysis was carried out through composite interval mapping (CIM) for linkage groups using WinQTLCart 2.5 (Wang et al. 2007) and interval mapping (IM) for unlinked markers using MapQTL 5.0 (Van Ooijen 2004). The threshold of the LOD score for determining the significance of a QTL was determined according to a permutation test with 1,000 runs. The LOD peaks of the significant QTLs were considered the QTL locations on the linkage map.

Chromosomal assignment of the FHB resistance QTLs. The linked SSR markers were assigned to specific chromosomes (Röder et al. 1998 a, b; Somers et al. 2004), but microsatellite markers are not always chromosome-specific because of shared partial homology (Plaschke et al. 1996). Therefore, to further ensure the accurate chromosomal location of the linked microsatellite markers, the following lines were used: Chinese Spring nullisomic 2A tetrasomic 2B (N2AT2B), nullisomic 2A tetrasomic 2D (N2AT2D), nullisomic 2B tetrasomic 2A (N2BT2A), nullisomic 2B tetrasomic 2D (N2BT2D), nullisomic 2D tetrasomic 2A (N2DT2A), nullisomic 2D tetrasomic 2B (N2DT2B), nullisomic 3A tetrasomic 3B (N3AT3B), nullisomic 3A tetrasomic 3D (N3AT3D), nullisomic 3B tetrasomic 3A (N3BT3A), nullisomic 3B tetrasomic 3D (N3BT3D), nullisomic 3D tetrasomic 3A (N3DT3A), and nullisomic 3D tetrasomic 3B (N3DT3B). All lines were provided by D. C. Liu, Triticeae Research Institute, Sichuan Agricultural University, Chengdu, Sichuan.

\section{RESULTS}

FHB reaction in the $F_{2}$ and $F_{2: 3}$ populations. The FHB resistance test revealed that PI 672538 was resistant to FHB; L661 was susceptible to FHB (Fig. 1); and their respective PDS, PDK, and KGW values were different at $P=0.05$ (Table 1) (Liu et al. 2015). The data in Table 1 and Supplementary Table $S 2$ show that all three resistance parameters exhibited continuous variation to some degree. The distribution of the resistance parameters is shown in Figure 2. The $F_{2}$ population in 2011 exhibited two peaks in the PDS, whereas the $\mathrm{F}_{2: 3}$ population in 2012 exhibited only one peak; the average PDS in the $\mathrm{F}_{2: 3}$ population is lower than that in the $\mathrm{F}_{2}$ population (Fig. $2 \mathrm{~A}$ ). The PDK and KGW showed only one peak in both populations (Fig. $2 \mathrm{~B}$ and $\mathrm{C}$ ). The data in Table 1 and the distribution of the resistance parameters in Figure 2 imply that FHB resistance is controlled by more than one gene.

The correlation analysis between the $\mathrm{F}_{2}$ and $\mathrm{F}_{2: 3}$ populations revealed a significant relevance of the PDS and PDK at $P=0.05$ (Table 2); only the relationship between the $\mathrm{KGW}$ of the $\mathrm{F}_{2: 3}$ population and the three parameters of the $\mathrm{F}_{2}$ population was not significant, whereas all other relationships both within populations and among populations were significant at the $P=0.05$ level.

Linkage molecular marker screening. We originally found that two SSR markers, Xwmc 441 on chromosome 2B and Xgwm566 on chromosome $3 \mathrm{~B}$, out of the 41 primary polymorphic SSR markers from the $g w m$ and $w m c$ series were associated with FHB resistance. Following this, we further screened all available markers on $2 \mathrm{~B}$ and $3 \mathrm{~B}$ and found that 22 markers covering $135.51 \mathrm{cM}$ with an average distance of $6.15 \mathrm{cM}$ between the two markers and 19 markers on 3B covering $96.77 \mathrm{cM}$ with an average distance of $5.38 \mathrm{cM}$ were linked with FHB resistance. The order of the markers on the chromosomes corresponds well with the reference genetic map (Supplementary Figs. S1, S2, and S3) (Somers et al. 2004).

Mapping of major QTLs. From the 1000-run permutation test, the threshold of the LOD value was determined at 2.5, when the QTL possibility is greater than $95 \%$. We detected two QTLs by composite interval mapping (CIM) using WinQTLCart 2.5 for PDS on chromosomes $2 \mathrm{~B}$ and $3 \mathrm{~B}$ : one on $2 \mathrm{~B}$ and two closely linked QTLs on $3 B$. In the $F_{2}$ population, the QTL on $2 B$ was flanked by markers Xbarc55-2B and Xcnl6-2B, explaining $11.6 \%$ of the phenotypic variation, and the QTL on chromosome $3 \mathrm{~B}$ was flanked by $X w m c 54-3 B$ and $X w m c 615-3 B$. In the $\mathrm{F}_{2: 3}$ population, the QTL on 2B was flanked by Xbarc55-2B and Xbarc1155-2B, explaining $7.1 \%$ of the phenotypic variation, and the QTL on $3 \mathrm{~B}$ was flanked by Xwmc54-3B and Xgwm566-3B, explaining $10 \%$ of the phenotypic variation. In addition, we also detected the QTLs for PDK and KGW in both populations at similar chromosomal locations (Table 3).

The data in Table 3 and Figure 3 show that the FHB resistance in this study was mainly controlled by two QTLs on $2 \mathrm{~B}$ and $3 \mathrm{~B}$, designated $Q f h s-2 B$ and $Q f h s-3 B$. $Q f h s-2 B$ was flanked by markers $X$ barc55-2B and Xbarc1155-2B (Fig. 3), and $Q f h s-3 B$ was flanked by $X w m c 231-3 B$ and $X w m c 54-3 B$ (Fig. 3). Based on the major effect, we designated $Q f h s-2 B$ as FhbL693a and $Q f h s-3 B$ as FhbL693b.

Chromosome assignment of the major QTLs. Based on the published chromosomal locations of the linked markers (Röder et al. 1998 a, b; Somers et al. 2004; Song et al. 2002), Qfhs-thin-2B and Qfhs-thin-3B were located on chromosome 2B and 3B, respectively. We further verified the chromosomal location of the linked markers with Chinese Spring nulli-tetrasomic lines (Table 4). Seventeen out of the 22 markers linked with $Q f h s-2 B$ were specific 
to chromosome 2B, and 14 out of 19 markers linked with $Q f h s-3 B$ were specific to chromosome 3B. Therefore, Qfhs-2B (FhbL693a) and $Q f h s-3 B(F h b L 693 b)$ were mapped on $2 \mathrm{~B}$ and 3B, respectively.

\section{DISCUSSION}

The mode of inheritance of FHB resistance. Growing resistant cultivars is one of the most effective, economical, and environmentally sound measures for controlling wheat FHB; therefore, identifying new sources of FHB resistance is very important in wheat breeding programs (Zhang et al. 2008). PI 672538 showed resistance to wheat FHB in different locations and years (Fig. 1) (Yang et al. 2016). Although there was no difference in the PDS between PI 672538 and the known resistant controls Sumai 3 and Wangshuibai, the PDS of PI 672538 was slightly lower than that of Sumai 3 and Wangshuibai (Liu et al. 2015). In addition to FHB resistance, PI 672538 was resistant to stripe rust (Huang et al. 2014), powdery mildew (Liu et al. 2015; Ma et al. 2015). Therefore, PI 672538 is valuable wheat germplasm for the improvement of wheat disease resistance.

Elucidating the inheritance of FHB resistance in PI 672538 is critical to the utilization of PI 672538 in wheat breeding. FHB resistance has usually been treated as a quantitative trait controlled by multiple genes (reviewed by Buerstmayr et al. 2009). Genetic analysis demonstrated that the genes for FHB resistance in Sumai 3 were assigned to chromosomes 2A, 5A, 7A, 1B, 2B, 3B, 6B, 6D, and 7D (Yao et al. 1996; Yu 1982). Consequently, further study revealed that FHB resistance was mainly conferred by the major QTL $F h b 1$ (Cuthbert et al. 2006), which implied a few QTLs with a large effect on FHB resistance.

In this study, the PDS data distribution exhibited two peaks in the $F_{2}$ population in 2011 but only one peak in the $F_{2: 3}$ population in 2012 (Fig. 2), which implies that the FHB resistance of PI 672538 is controlled by more than one gene, even though the number of genes responsible for this resistance is small. In addition, our previous studies showed that the resistance response of PI 672538 was different from those of other published germplasms (Liu et al. 2015), which further indicated that the genetic component of FHB resistance is possibly different from other FHB-resistant germplasms.

Chromosomal location and genetic mapping of FHB resistance QTLs. We detected two QTLs using WinQTLCart 2.5 software (Wang et al. 2007) in the $\mathrm{F}_{2}$ and $\mathrm{F}_{2: 3}$ populations: Qfhsthin-2B and $Q$ fhs-thin-3B (Fig. 3). Almost all of the resistance parameters, including PDS, PDK, and KGW, exhibited good chromosomal agreement (Supplementary Fig. S4), which suggests that FHB QTLs exist in the chromosomal region. The locations of 17 out

TABLE 1. Means of Fusarium head blight resistance traits including the percentage of diseased spikelets (PDS), percentage of damaged kernels (PDK), and 1,000grain weight $(\mathrm{KGW})$ of the parent and population lines ${ }^{\mathrm{z}}$

\begin{tabular}{|c|c|c|c|c|c|c|c|c|c|c|}
\hline \multirow[b]{2}{*}{ Year } & \multirow[b]{2}{*}{ Line } & \multicolumn{3}{|c|}{ PDS } & \multicolumn{3}{|c|}{ PDK } & \multicolumn{3}{|c|}{ KGW (g) } \\
\hline & & Mean & SE & Sig & Mean & SE & Sig & Mean & SE & Sig \\
\hline \multirow[t]{3}{*}{2011} & $\mathrm{~F}_{2}$ mean & 0.457 & 0.166 & $\mathrm{~b}$ & 0.206 & 0.110 & $\mathrm{~b}$ & 19.837 & 0.504 & $\mathrm{~b}$ \\
\hline & L661 & 0.739 & 0.034 & $\mathrm{c}$ & 0.484 & 0.097 & $\mathrm{a}$ & 12.679 & 1.671 & $\mathrm{a}$ \\
\hline & PI 672538 & 0.161 & 0.019 & $\mathrm{a}$ & 0.073 & 0.064 & $\mathrm{c}$ & 24.666 & 1.074 & $\mathrm{c}$ \\
\hline \multirow[t]{3}{*}{2012} & $\mathrm{~F}_{2: 3}$ mean & 0.219 & 0.059 & $\mathrm{~b}$ & 0.482 & 0.096 & $\mathrm{~b}$ & 24.855 & 0.326 & $\mathrm{~b}$ \\
\hline & L661 & 0.534 & 0.062 & $\mathrm{c}$ & 0.748 & 0.089 & $\mathrm{a}$ & 18.982 & 2.334 & $\mathrm{a}$ \\
\hline & PI 672538 & 0.104 & 0.010 & $\mathrm{a}$ & 0.266 & 0.039 & $\mathrm{c}$ & 33.670 & 1.509 & $\mathrm{c}$ \\
\hline
\end{tabular}

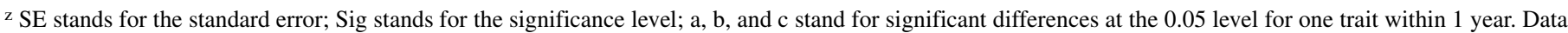
for PDS and KGW were published previously (Liu et al. 2015).
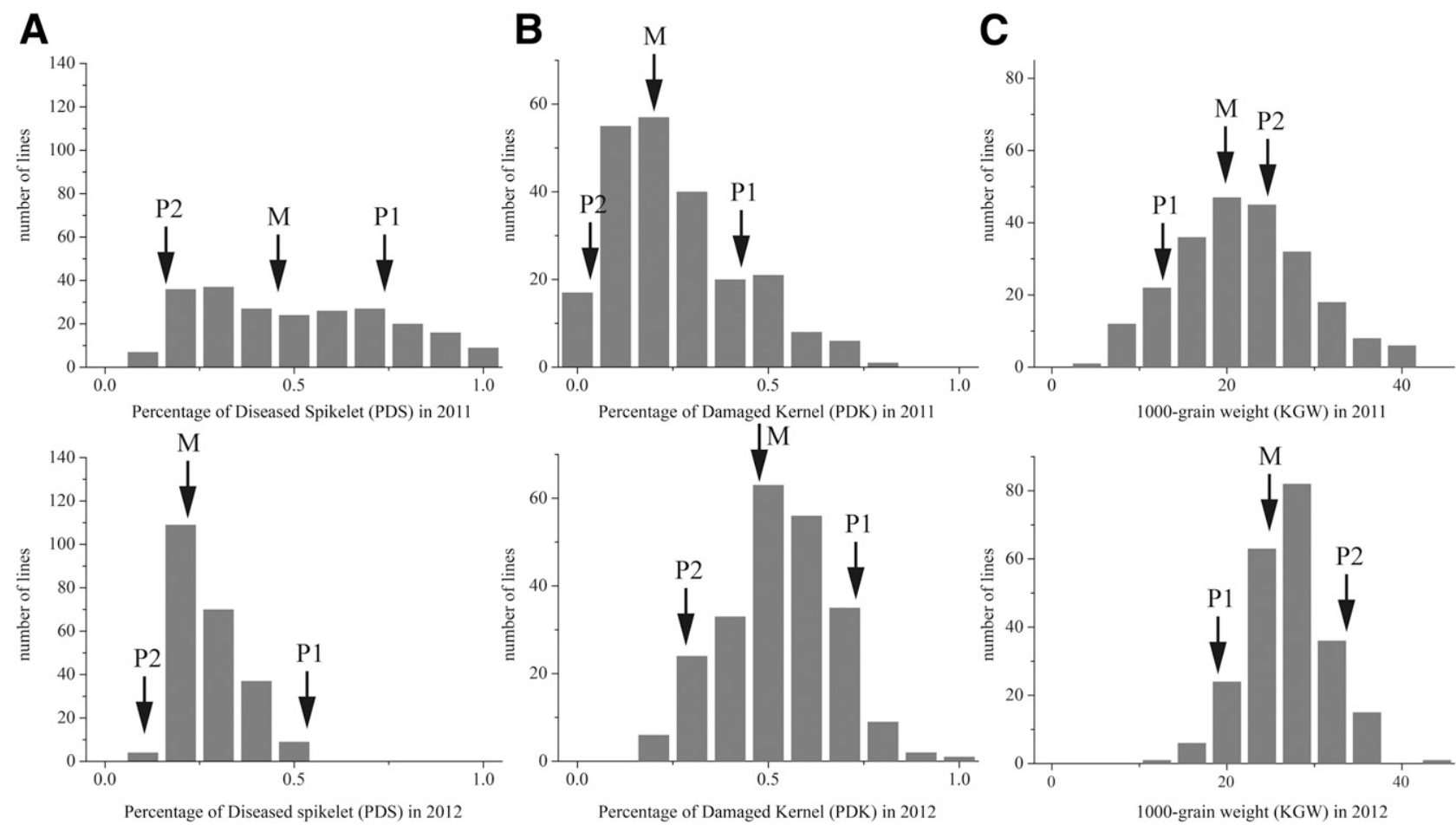

Fig. 2. Distribution of Fusarium head blight-related traits in the L661 $\times$ PI $672538 \mathrm{~F}_{2}$ population evaluated in 2011 and 2012. M, the mean of the population; P1, the parent line L661; P2, the parent line PI 672538. A, Distribution of the percentage of diseased spikelets (PDS). B, Distribution of the percentage of damaged kernels (PDK). C, Distribution of the 1,000-grain weight (KGW). 
of the 22 markers linked with $Q f h s$-thin- $2 B$ were further verified on chromosome 2B using the Chinese Spring nulli-tetrasomic line (Table 4, Shen et al. 2015). At the same time, the location 14 out of the 19 markers linked with $Q f h s$-thin-3B were also verified on chromosome $3 \mathrm{~B}$ using the same method (Table 4 ). The total genetic distance of the linkage mapping of $Q f h s-2 B$ was $130 \mathrm{cM}$, including 22 markers, and that of $Q f h s-3 B$ was $100 \mathrm{cM}$, including 19 markers.

To date, various researchers have detected the FHB resistance QTL on chromosome 2B from different plant materials, including Renan (Gervais et al. 2003) and Goldfield (Gilsinger et al. 2005) for type I resistance; Dream (Schmolke et al. 2005), Ernie (Liu et al. 2007), G16-92 (Schmolke et al. 2005), Triticum durum

TABLE 2. Correlation analysis between the field test data: the percentage of diseased spikelets (PDS), percentage of damaged kernels (PDK), and 1,000grain weight $(\mathrm{KGW})^{\mathrm{z}}$

\begin{tabular}{lcccccc}
\hline & PDS & KGW & PDK & PDS & KGW & PDK \\
& 2011 & 2011 & 2011 & 2012 & 2012 & 2012 \\
\hline PDS 2011 & & & & & \\
KGW 2011 & $-0.649^{* *}$ & & & & & \\
PDK 2011 & $0.776^{* *}$ & $-0.575^{* *}$ & & & & \\
PDS 2012 & $0.846^{* *}$ & $-0.522^{* *}$ & $0.574^{* *}$ & & \\
KGW 2012 & -0.112 & 0.052 & -0.01 & $-0.178^{* *}$ & \\
PDK 2012 & $0.522^{* *}$ & $-0.253^{* *}$ & $0.406^{* *}$ & $0.557^{* *}$ & $-0.222^{* *}$ \\
\hline z ** Indicates significant correlation at the 0.01 level (bilateral); * indicates \\
significant correlation at the 0.05 level (bilateral).
\end{tabular}

'Strongfield' (Somers et al. 2006) and Ning 7840 (Zhou et al. 2002) for type II resistance; and Frontana (Steiner et al. 2004) for both type I and type II resistance. However, only two major QTLs have been reported on chromosome $2 \mathrm{~B}$ to the best of our knowledge. QFhs. inra- $2 b$, flanked by Xgwm388-Xgwm257, was located on the centromere regions of chromosome $2 \mathrm{~B}$ mapped in the RILs derived from two European winter wheat cultivars, Renan and Récital (Gervais et al. 2003). The other QTL, named Qfhs.umc-2B, was linked with $X g w m 278-2 B$ on the chromosome arm 2BS and identified in the soft red winter wheat Ernie (Liu et al. 2007). We located a major QTL named $Q f h s-2 B$ on wheat chromosome $2 \mathrm{~B}$ that explained 9.2 to $11.6 \%$ of the phenotypic variation of the PDS (Fig. 3; Table 3). An FHB resistance QTL was reported in the chromosomal region in which $Q f h s-2 B$ was mapped in Triticum durum (Somers et al. 2006), but there was no report of the genetic background of this wheat (reviewed by Buerstmayr et al. 2009). Qfhs-2B mapped in this study explained 9.2 to $11.6 \%$ of the phenotypic variation for the PDS (Fig. 3; Table 3). $Q f h s-2 B$ was located on the distal end of the chromosome arm $2 \mathrm{BL}$, which is different from the previously reported QTLs; therefore, we designated $Q f h s$-thin- $2 B$ as FhbL693a.

FHB resistance QTLs on $3 \mathrm{~B}$ have been widely reported and mainly derived from Sumai 3 and its derivatives (Anderson et al. 2001; Ban and Suenaga 2000; Buerstmayr et al. 2002; Makandar et al. 2006), Wangshuibai (Lin et al. 2006; Mardi et al. 2005), and Frontana and its derivatives (Han et al. 2005; Mardi et al. 2006). The well-known FHB resistance QTL on 3BS is Fhbl, which is derived

TABLE 3. Quantitative trait loci (QTLs) in the L661 $\times$ PI 672538 inbred $F_{2}$ and $F_{2: 3}$ line populations associated with the percentage of diseased spikelets (PDS), percentage of damaged kernels (PDK), and 1,000-grain weight (KGW)

\begin{tabular}{|c|c|c|c|c|c|c|c|c|c|c|c|}
\hline Year & QTLs & Flanking markers & Range & Traits & $\mathrm{Chr}$ & Closest marker & Position (cM) & $\mathrm{LOD}^{\mathrm{z}}$ & Additive & Dominant & $R^{2}$ \\
\hline \multirow[t]{4}{*}{2011} & $Q$ & $1 B$ & 38 & KGW & 1B & $5.2-3 B$ & 10.56 & 2.82 & -2.498 & 2.248 & $6.9 \%$ \\
\hline & Qfhs & $X b \operatorname{arc} 55-2 B-X$ & 115.4 & PDS & $2 \mathrm{~B}$ & $64-2 B$ & 120.40 & 5.02 & 0.122 & -0.056 & $11.6 \%$ \\
\hline & Qfhs & Хwmc54-3B-Хwmc615-3B & $26.55-34.18$ & KGW & 3B & Xwmo & 27.55 & 5.50 & 3.292 & 4.461 & $8.7 \%$ \\
\hline & & Xwmc54-3B-Xwmc615-3B & $27.55-34.18$ & PDS & 3B & $X c f d 4-3 B$ & 29.18 & 5.92 & -0.029 & -0.141 & $0.4 \%$ \\
\hline \multirow[t]{3}{*}{2012} & Qfhs-thin- $1 B$ & Хwmc419-1B-Xbarc $187-1 B$ & $0.01-25.88$ & KGW & 1B & Xgwm11-1B & 16.88 & 10.37 & -3.117 & 1.758 & $27 \%$ \\
\hline & Qfhs-thin- $2 B$ & $155-2 B$ & 117. & KGW & 2B & Xcnl & 130 & 3.63 & -2 . & & $9.2 \%$ \\
\hline & & $-2 B$ & $115.4-1$ & PDS & $2 \mathrm{~B}$ & $1064-2 B$ & 119.40 & 3.11 & 0.035 & -0.008 & $7.1 \%$ \\
\hline
\end{tabular}

$\mathrm{z}$ The critical logarithm of the odds (LOD) threshold of 2.5 for the 0.05 level of probability was obtained through a 1,000-run permutation test.

A

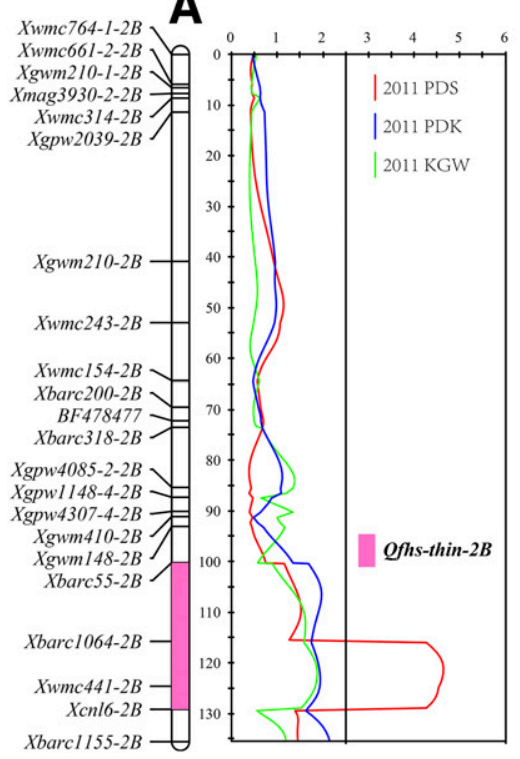

B

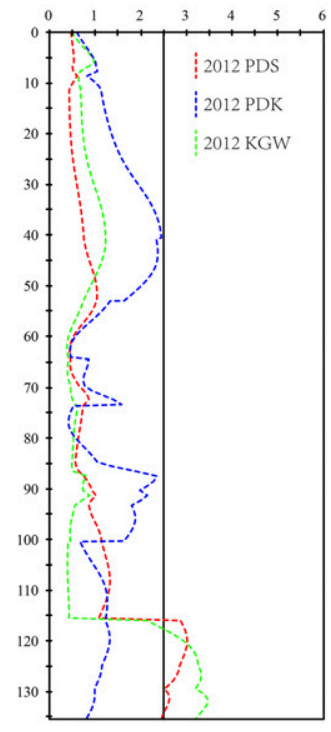

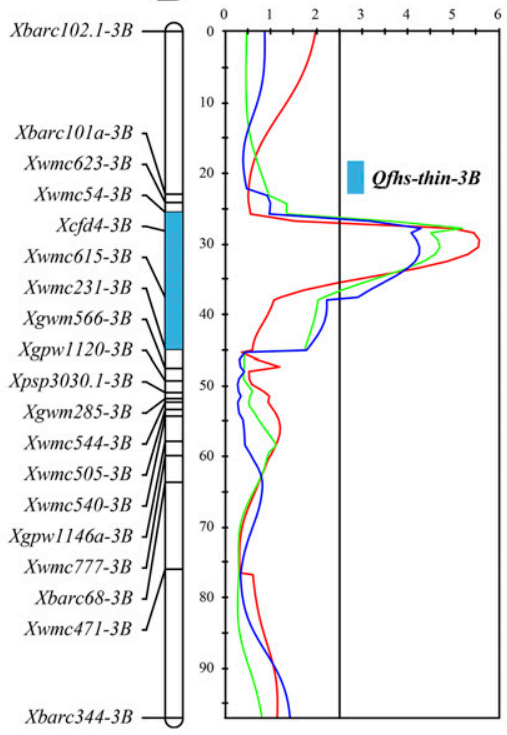

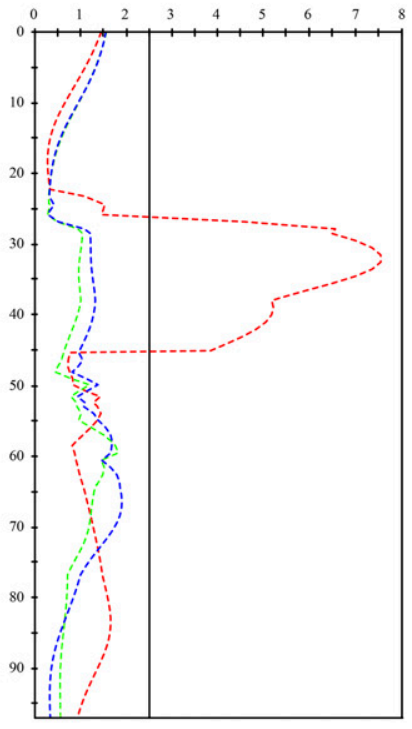

Fig. 3. Quantitative trait loci (QTLs) for the four Fusarium head blight-related traits on the four linkage groups in 2011 (left) and 2012 (right). The $x$-axis is the Morgan distance (cM); the y-axis is the LOD value. A, Two QTLs on the linkage group of wheat chromosome 2B in 2011, and three QTLs in 2012. B, Three QTLs on the linkage group of wheat chromosome 3B in 2011, and one QTL in 2012. 
from Sumai 3 and has been mapped between Xgwm493 and Xgwm533 (Cuthbert et al. 2006). In our study, $Q f h s-3 B$ was also mapped on the chromosome arm 3BS, which was flanked by Xwmc231-3B and $X w m c 54-3 B$ and was closer to the centromere region compared with Fhbl (Fig. 3), implying that $Q f h s-3 B$ is not Fhbl (Supplementary Fig. S5). In addition, the resistance response of PI 672538 also obviously differs from that of Sumai 3 (Zhang et al. 2011; Liu et al. 2015), and the pedigree of PI 672538 and L661 did not contain Sumai 3 or its derivatives (Liu et al. 2015; Zhang et al. 2011). Most importantly, we did not detect Fhbl in the parent lines PI 672538 and L661 using the diagnostic markers cfb6058 and cg8-Agro developed by Professor Guihua Bai's group (G. Bai and Z. Su at Kansas State University, personal communication; Supplementary Figs. S6 and S7). Considering all of the evidence, we can conclude that $Q f h s-3 B$ is different from $F h b l$ and is therefore designated as FhbL693b.

In addition, we also observed differences in the contribution size and existence of QTLs detected on 2B and 3B between 2011 and 2012 (Table 3; Fig. 3) that possibly resulted from three main phenomena. First, the FHB resistance was mainly afforded by the QTLs, which can be easily influenced by environmental variations (Anderson et al. 2001). Second, the sample size in 2011 was small compared with that in 2012 because of the randomly segregated $F_{2}$ individuals. Finally and more importantly, the difference in the genetic components of $F_{2}$ and $F_{2: 3}$ could have influenced the phenotypic data distribution.

Origin of FHB resistance and the putative mechanism of FHB resistance transfer. Alien chromosomal translocation is usually employed for transferring valuable genes from wild relative to wheat. Transferring large chromosome segments, often carrying genes for both desirable and undesirables traits and resulting in 'linkage drag', has not been widely used in wheat breeding (Young and Tanksley 1989). However, cryptic translocation with only the traits of interest and without detectable cytological or genetic changes has been reported (Kuraparthy et al. 2007). Thinopyrum intermedium is in the pedigree of both PI 672538 and L661. A recent study demonstrated that the YU25, PI 672538, and L661 wheat genotypes do not have a cytologically detectable alien chromosome segment and therefore may contain a cryptic translocation (Li et al. 2015). In addition, wheat-specific products were amplified by almost all of the wheat SSR primers, evenly distributed over all of the chromosomal arms with small spaces, which also indicates that a large foreign chromosomal segment is not present in PI 672538 or L661 (Huang et al. 2014; Li et al. 2015). This observation is similar to that observed in YU25 (Luo et al. 2009a, b). Therefore, we cannot exclude the possibility that the FHB resistance in PI 672538 was

TABLE 4. Linkage markers in groups $2 \mathrm{~B}$ and $3 \mathrm{~B}$

\begin{tabular}{|c|c|c|c|c|c|}
\hline Markers & Forward primer $5^{\prime}-3^{\prime}$ & Reverse primer $5^{\prime}-3^{\prime}$ & $\mathrm{CM}$ & $\begin{array}{c}\text { Chromosome } \\
\text { location }\end{array}$ & Type \\
\hline$X w m c 764-1-2 B^{w}$ & AACAAAGCGTGCCTAATGCT & CCTGAAGCTCTGATGCCAAT & 0 & $2 \mathrm{~B}$ & Codominant \\
\hline$X w m c 661-2-2 B^{w}$ & GAGAGGAGGCCTCACACTTTT & CATGTGGCATCGTGATGAAT & 5.884 & $2 \mathrm{~B}$ & Dominant \\
\hline Xmag3930-2-2Bw & TTGCATTTGCTTGATGATGG & CTGATCCCATGAAACCAAGG & 7.682 & $2 \mathrm{~B}$ & Codominant \\
\hline$X w m c 314-2 B^{\mathrm{x}}$ & ACACGGGGTCTGATTGCTTTAC & ATCGCTTTTTGACAAGTGAGGC & 8.603 & $2 \mathrm{~B}$ & Dominant \\
\hline$X g p w 2039-2 B^{\mathrm{x}}$ & ACCGGGAGTCCTTGTCTTTT & AGCTTACCAGGTCGGACAAA & 11.346 & $2 \mathrm{~B}$ & Dominant \\
\hline Xgwm 210-2B & TGCATCAAGAATAGTGTGGAAG & TGAGAGGAAGGCTCACACCT & 40.732 & $2 \mathrm{~A}, 2 \mathrm{D}$ & Dominant \\
\hline$X$ barc $200-2 B^{\mathrm{x}}$ & AGCTTACCAGGTCGGACAAA & GCGATATGATTTGGAGCTGATTG & 69.314 & $2 \mathrm{~B}$ & Dominant \\
\hline BF478477y & AGCTACTCCACGCCTCAGTA & AGCCCAGAGTAAGCAGCATC & 71.972 & $2 \mathrm{~B}$ & Dominant \\
\hline$X \operatorname{barc} 318-2 B^{\mathrm{x}}$ & CGACTAACAATTTTTCATTT & TGATTTCGCTAACAAGGAG & 73.266 & $2 \mathrm{~B}$ & Codominant \\
\hline$X g p w 4085-2-2 B^{w}$ & TTTTGAGTTGGGCTGGTTTC & AGGTCATGGCCTGTTGTTTC & 85.083 & $2 \mathrm{~B}$ & Dominant \\
\hline Xgpw1148-6-2Bw & GCATGCATAACACCAACGTC & GCTCGGGTACATTTTGTGCT & 87.021 & $2 \mathrm{~B}$ & Codominant \\
\hline Xgpw4307-4-2Bw & TGCATGATGTAATAAACTCCC & CAAAGAGAAAGGGGGACACA & 89.81 & $1 \mathrm{D}$ & Codominant \\
\hline Xgwm $410-2 B^{\mathrm{x}}$ & GCTTGAGACCGGCACAGT & CGAGACCTTGAGGGTCTAGA & 90.838 & $2 \mathrm{~B}$ & Codominant \\
\hline Xbarc1155-2B & TGCAAACATGAAAACAATCCTCCAC & TCCACCTCGTCCTCCTCTACACC & 135.151 & $2 \mathrm{~B}$ & Dominant \\
\hline Xbarc 102.1-3B & GGAGAGGACCTGCTAAAATCGAAGACA & GCGTTTACGGATCAGTGTTGGAGA & 0 & $3 \mathrm{~B}$ & Dominant \\
\hline Xbarc 101a-3B & GCTCCTCTCACGATCACGCAAAG & GCGAGTCGATCACACTATGAGCCAATG & 22.97 & $3 \mathrm{~B}$ & Dominant \\
\hline$X w m c 623-3 B^{\mathrm{x}}$ & ACGATTGGCCACAGAGGAG & CAGTGACCAATAGTGGAGGTCA & 24.168 & Ambiguous $^{\mathrm{z}}$ & Codominant \\
\hline$X w m c 54-3 B^{\mathrm{x}}$ & TATTGTGCAATCGCAGCATCTC & TGCGACATTGGCAACCACTTCT & 25.54 & $3 \mathrm{~B}$ & Codominant \\
\hline$X c f d 4-3 B^{\mathrm{x}}$ & TGCTCCGTCTCCGAGTAGAT & GGGAAGGAGAGATGGGAAAC & 28.172 & $3 \mathrm{~B}, 3 \mathrm{D}$ & Codominant \\
\hline Xwmc615-3B & TGCCCACAACTTATCTCAG & GGTAAGTGGCCCAGGTAGT & 37.552 & $3 \mathrm{~B}$ & Dominant \\
\hline$X w m c 231-3 B^{\mathrm{x}}$ & CATGGCGAGGAGCTCGGTGGTC & GTGGAGCACAGGCGGAGCAAGG & 44.822 & $3 \mathrm{~B}$ & Codominant \\
\hline Xgwm $566-3 B^{\mathrm{x}}$ & TCTGTCTACCCATGGGATTTG & CTGGCTTCGAGGTAAGCAAC & 47.46 & 3B & Dominant \\
\hline Xgpw1120-3B & ATTGCGCAAGATTGGTAGGT & AAGCGATGCTACCCCATAAA & 49.234 & $3 \mathrm{~B}$ & Codominant \\
\hline Xpsp3030.1-3B & GATCGGCTGAGAAAAGAGGC & TTGTTGACTTGGTCAGTCGG & 50.882 & $3 \mathrm{~B}$ & Codominant \\
\hline Xgwm $285-3 B^{\mathrm{x}}$ & ATGACCCTTCTGCCAAACAC & ATCGACCGGGATCTAGCC & 51.72 & $3 \mathrm{~B}$ & Codominant \\
\hline Xwmc544-3B & CCATTTGAGGTTTGGTCGCTAC & TATATGTGATTTGTCGTGCCCC & 52.22 & $3 \mathrm{~B}$ & Dominant \\
\hline$X w m c 505-3 B^{\mathrm{x}}$ & AGGGGAGGAAAACCTTGTAATC & ACGACCTACGTGGTAGTTCTTG & 53.247 & $3 \mathrm{~A}, 3 \mathrm{~B}$ & Dominant \\
\hline
\end{tabular}

${ }^{w}$ Newly developed simple sequence repeat (SSR) markers.

$x$ Published SSR markers.

y Newly developed EST markers.

${ }^{\mathrm{z}}$ Marker location cannot be determined by nulli-tetrasomic lines. 
transferred from Thinopyrum intermedium into wheat by cryptic translocation.

In addition, we also cannot exclude the possibility that the FHB resistance in PI 672538 resulted from DNA sequence changes in the wheat genome during wide crosses. In rice, DNA sequence deletion resulted in the production of a new blast resistance gene Pi21 (Fukuoka et al. 2009). In PI 672538, a 36-bp deletion of a wheat DNA sequence on 1B resulted in a putative wheat copper-binding protein $(W C B P 1)$ that conferred resistance to strip rust ( $\mathrm{Li}$ et al. 2015). Based on the available evidence, we cannot be certain whether FhbL693a and FhbL693b were directly transferred from Thinopyrum intermedium into wheat or were indirectly produced by DNA sequence changes, especially deletions. This problem will be clarified by our future work.

Potential utilization of the FHB resistance QTLs in wheat breeding programs. Concerning wheat FHB resistance, Sumai 3, Wangshuibai, and their derivatives are well-known sources of FHB resistance, and the major resistance QTL $F h b l$ is located on the chromosomal arm 3BS (Cuthbert et al. 2006). However, it is difficult to use these sources in wheat breeding because they have many undesired agronomic traits. In our study, PI 672538 was highly resistant to wheat stripe rust and powdery mildew, in addition to its FHB resistance. Therefore, this germplasm will play an important role in improving wheat disease resistance because more attention is usually paid to the disease resistance level and comprehensive agronomic traits than to the genetic mechanism. In addition, PI 672538 and its derivatives have been widely used in wheat breeding programs in Henan, Shandong, Beijing, and Sichuan provinces. Therefore, PI 672538 will be an important diseaseresistant source in the future.

\section{ACKNOWLEDGMENTS}

We thank the National Natural Science Foundation of China (31271721 and 31571661), the Key Projects of the Education Ministry of China (2012146), the Specific Foundation of Agronomy (nyhyzx3-15, 201303016), the bureau of Science and Technology of Fuling of Chongqing (FLKJ-2015ABB1048), and the Ministry of Science and Technology, China (2013CB127701) for financial support. We thank G. H. Bai (Kansas State University) for critically reviewing a draft of this manuscript.

\section{LITERATURE CITED}

Anderson, J. A., Stack, R. W., Liu, S., Waldron, B. L., Fjeld, A. D., Coyne, C., Moreno-Sevilla, B., Fetch, J. M., Song, Q. J., Cregan, P. B., and Frohberg, R. C. 2001. DNA markers for Fusarium head blight resistance QTLs in two wheat populations. Theor. Appl. Genet. 102:1164-1168.

Bai, G., and Shaner, G. 2004. Management and resistance in wheat and barley to Fusarium head blight. Annu. Rev. Phytopathol. 42:135-161.

Ban, T., and Suenaga, K. 2000. Genetic analysis of resistance to Fusarium head blight caused by Fusarium graminearum in Chinese wheat cultivar Sumai 3 and the Japanese cultivar Saikai 165. Euphytica 113:87-99.

Bassam, B. J., Caetano-Anollés, G., and Gresshoff, P. M. 1991. Fast and sensitive silver staining of DNA in polyacrylamide gels. Anal. Biochem. 196:80-83

Bryan, G. J., Collins, A. J., Stephenson, P., Orry, A., Smith, J. B., and Gale, M. D. 1997. Isolation and characterisation of microsatellites from hexaploid bread wheat. Theor. Appl. Genet. 94:557-563.

Buerstmayr, H., Ban, T., and Anderson, J. A. 2009. QTL mapping and markerassisted selection for Fusarium head blight resistance in wheat: a review. Plant Breed. 128:1-26.

Buerstmayr, H., Lemmens, M., Hartl, L., Doldi, L., Steiner, B., Stierschneider, M., and Ruckenbauer, P. 2002. Molecular mapping of QTLs for Fusarium head blight resistance in spring wheat. I. Resistance to fungal spread (type II resistance). Theor. Appl. Genet. 104:84-91.

Cai, J., and Bai, G. 2014. Quantitative trait loci for Fusarium head blight resistance in Huangcandou $\times$ 'Jagger' wheat population. Crop Sci. 54: 2520-2528.

Cainong, J. C., Bockus, W. W., Feng, Y., Chen, P., Qi, L., Sehgal, S. K., Danilova, T. V., Koo, D.-H., Friebe, B., and Gill, B. S. 2015. Chromosome engineering, mapping, and transferring of resistance to Fusarium head blight disease from Elymus tsukushiensis into wheat. Theor. Appl. Genet. 128:1019-1027.
Cuthbert, P. A., Somers, D. J., and Brulé-Babel, A. 2007. Mapping of Fhb2 on chromosome 6BS: A gene controlling Fusarium head blight field resistance in bread wheat (Triticum aestivum L.). Theor. Appl. Genet. 114:429-437.

Cuthbert, P. A., Somers, D. J., Thomas, J., Cloutier, S., and Brulé-Babel, A. 2006. Fine mapping Fhb1, a major gene controlling Fusarium head blight resistance in bread wheat (Triticum aestivum L.). Theor. Appl. Genet. 112: $1465-1472$.

Dvorjak, D. S. 2014. Fusarium head blight resistance and agronomic performance in soft red winter wheat populations. Ph.D. dissert., University of Kentucky, Department of Plant and Soil Sciences.

Fedak, G., and Han, F. 2005. Characterization of derivatives from wheatThinopyrum wide crosses. Cytogenet. Genome Res. 109:360-367.

Fukuoka, S., Saka, N., Koga, H., Ono, K., Shimizu, T., Ebana, K., Hayashi, N., Takahashi, A., Hirochika, H., Okuno, K., and Yano, M. 2009. Loss of function of a proline-containing protein confers durable disease resistance in rice. Science 325:998-1001.

Gervais, L., Dedryver, F., Morlais, J.-Y., Bodusseau, V., Negre, S., Bilous, M., Groos, C., and Trottet, M. 2003. Mapping of quantitative trait loci for field resistance to Fusarium head blight in a European winter wheat. Theor. Appl. Genet. 106:961-970.

Gilsinger, J., Kong, L., Shen, X., and Ohm, H. 2005. DNA markers associated with low Fusarium head blight incidence and narrow flower opening in wheat. Theor. Appl. Genet. 110:1218-1225.

Guo, J., Zhang, X., Hou, Y., Cai, J., Shen, X., Zhou, T., Xu, H., Ohm, H. W., Wang, H., Li, A., Han, F., Wang, H., and Kong, L. 2015. High-density mapping of the major FHB resistance gene $F h b 7$ derived from Thinopyrum ponticum and its pyramiding with $F h b 1$ by marker-assisted selection. Theor. Appl. Genet. 128:2301-2316.

Gupta, K., Balyan, S., Edwards, J., Isaac, P., Korzun, V., Röder, M., Gautier, M. F., Joudrier, P., Schlatter, R., Dubcovsky, J., De La Pena, C., Khairallah, M., Penner, G., Hayden, J., Sharp, P., Keller, B., Wang, C., Hardouin, P., Jack, P., and Leroy, P. 2002. Genetic mapping of 66 new microsatellite (SSR) loci in bread wheat. Theor. Appl. Genet. 105:413-422.

Guyomarc'h, H., Sourdille, P., Charmet, G., Edwards, J., and Bernard, M. 2002. Characterisation of polymorphic microsatellite markers from Aegilops tauschii and transferability to the D-genome of bread wheat. Theor. Appl. Genet. 104:1164-1172.

Han, F. P., Fedak, G., Ouellet, T., Dan, H., and Somers, D. J. 2005. Mapping of genes expressed in Fusarium graminearum-infected heads of wheat cultivar 'Frontana'. Genome 48:88-96.

Huang, Q., Li, X., Chen, W. Q., Xiang, Z. P., Zhong, S. F., Chang, Z. J., Zhang, M., Zhang, H. Y., Tan, F. Q., Ren, Z. L., and Luo, P. G. 2014. Genetic mapping of a putative Thinopyrum intermedium-derived stripe rust resistance gene on wheat chromosome 1B. Theor. Appl. Genet. 127:843-853.

Kolb, F. L., Bai, G., Muehlbauer, G. J., Anderson, J. A., Smith, K. P., and Fedak, G. 2001. Host plant resistance genes for Fusarium head blight. Crop Sci. 41:611-619.

Kosambi, D. D. 1943. The estimation of map distances from recombination values. Ann. Eugen. 12:172-175.

Kuraparthy, V., Sood, S., Chhuneja, P., Dhaliwal, H. S., Kaur, S., Bowden, R. L., and Gill, B. S. 2007. A cryptic wheat-Aegilops triuncialis translocation with leaf rust resistance gene Lr58. Crop Sci. 47:1995-2003.

Li, X., Liu, T., Chen, W., Zhong, S., Zhang, H., Tang, Z., Chang, Z., Wang, L., Zhang, M., Li, L., Rao, H., Ren, Z., and Luo, P. 2015. Wheat WCBP1 encodes a putative copper-binding protein involved in stripe rust resistance and inhibition of leaf senescence. BMC Plant Biol. 15:239.

Lin, F., Xue, S. L., Zhang, Z. Z., Zhang, C. Q., Kong, Z. X., Yao, G. Q., Tian, D. G., Zhu, H. L., Li, C. J., Cao, Y., Wei, J. B., Luo, Q. Y., and Ma, Z. Q. 2006. Mapping QTL associated with resistance to Fusarium head blight in the Nanda2419 $\times$ Wangshuibai population. II: Type I resistance. Theor. Appl. Genet. 112:528-535.

Liu, J., Chang, Z., Zhang, X., Yang, Z., Li, X., Jia, J., Zhan, H., Guo, H., and Wang, J. 2013. Putative Thinopyrum intermedium-derived stripe rust resistance gene $\operatorname{Yr} 50$ maps on wheat chromosome arm 4BL. Theor. Appl. Genet. 126:265-274.

Liu, S., Abate, Z. A., Lu, H., Musket, T., Davis, G. L., and McKendry, A. L. 2007. QTL associated with Fusarium head blight resistance in the soft red winter wheat Ernie. Theor. Appl. Genet. 115:417-427.

Liu, S., Zhang, X., Pumphrey, M. O., Stack, R. W., Gill, B. S., and Anderson, J. A. 2006. Complex microcolinearity among wheat, rice, and barley revealed by fine mapping of the genomic region harboring a major QTL for resistance to Fusarium head blight in wheat. Funct. Integr. Genomics 6:83-89.

Liu, Z., Xu, M., Xiang, Z., Li, X., Chen, W., and Luo, P. 2015. Registration of the novel wheat lines L658, L693, L696, and L699, with resistance to Fusarium head blight, stripe rust, and powdery mildew. J. Plant Registrations 9:121-124.

Luo, P., Hu, X., Chang, Z., Zhang, M., Zhang, H., and Ren, Z. 2009a. A new stripe rust resistance gene transferred from Thinopyrum intermedium to hexaploid wheat (Triticum aestivum). Phytoprotection 90:57-63. 
Luo, P. G., Hu, X. Y., Ren, Z. L., Zhang, H. Y., Shu, K., and Yang, Z. J. 2008. Allelic analysis of stripe rust resistance genes on wheat chromosome $2 \mathrm{BS}$. Genome 51:922-927.

Luo, P. G., Luo, H. Y., Chang, Z. J., Zhang, H. Y., Zhang, M., and Ren, Z. L. 2009b. Characterization and chromosomal location of Pm40 in common wheat: Anew gene for resistance to powdery mildew derived from Elytrigia intermedium. Theor. Appl. Genet. 118:1059-1064.

Ma, L. X., Zhong, S. F., Liu, N., Chen, W. Q., Liu, T. G., Li, X., Zhang, M., Ren, Z. L., Yang, J. Z., and Luo, P. G. 2015. Gene expression profile and physiological and biochemical characterization of hexaploid wheat inoculated with Blumeria graminis f. sp. tritici. Physiol. Mol. Plant Pathol. 90:39-48.

Ma, Z., Xue, S., Lin, F., Yang, S., Li, G., Tang, M., Kong, Z., Cao, Y., Zhao, D., Jia, H., Zhang, Z., and Zhang, L. 2008. Mapping and validation of scab resistance QTLs in the Nanda2419 × Wangshuibai population. Cereal Res. Commun. 36:245-251.

Ma, Z. Q., Röder, M., and Sorrells, M. E. 1996. Frequencies and sequence characteristics of di-, tri-, and tetra-nucleotide microsatellites in wheat. Genome 39:123-130.

Makandar, R., Essig, J. S., Schapaugh, M. A., Trick, H. N., and Shah, J. 2006. Genetically engineered resistance to Fusarium head blight in wheat by expression of Arabidopsis NPR1. Mol. Plant-Microbe Interact. 19:123-129.

Mardi, M., Buerstmayr, H., Ghareyazie, B., Lemmens, M., Mohammadi, S. A., Nolz, R., and Ruckenbauer, P. 2005. QTL analysis of resistance to Fusarium head blight in wheat using a 'Wangshuibai'-derived population. Plant Breed. 124:329-333.

Mardi, M., Pazouki, L., Delavar, H., Kazemi, M. B., Ghareyazie, B., Steiner, B., Nolz, R., Lemmens, M., and Buerstmayr, H. 2006. QTL analysis of resistance to Fusarium head blight in wheat using a 'Frontana'-derived population. Plant Breed. 125:313-317.

Mesterhazy, A. 1995. Types and components of resistance to Fusarium head blight of wheat. Plant Breed. 114:377-386.

Plaschke, J., Börner, A., Wendehake, K., Ganal, M. W., and Röder, M. S. 1996. The use of wheat aneuploids for the chromosomal assignment of microsatellite loci. Euphytica 89:33-40.

Qi, L. L., Pumphrey, M. O., Friebe, B., Chen, P. D., and Gill, B. S. 2008. Molecular cytogenetic characterization of alien introgressions with gene Fhb3 for resistance to Fusarium head blight disease of wheat. Theor. Appl. Genet. 117:1155-1166.

Röder, M. S., Korzun, V., Gill, B. S., and Ganal, M. W. 1998a. The physical mapping of microsatellite markers in wheat. Genome 41:278-283.

Röder, M. S., Korzun, V., Wendehake, K., Plaschke, J., Tixier, M.-H., Leroy, P., and Ganal, M. W. 1998b. A microsatellite map of wheat. Genetics 149:2007-2023.

Rudd, J. C., Horsley, R. D., McKendry, A. L., and Elias, E. M. 2001. Host plant resistance genes for Fusarium head blight. Crop Sci. 41:620-627.

Schmolke, M., Zimmermann, G., Buerstmayr, H., Schweizer, G., Miedaner, T., Korzun, V., Ebmeyer, E., and Hartl, L. 2005. Molecular mapping of Fusarium head blight resistance in the winter wheat population dream/Lynx. Theor. Appl. Genet. 111:747-756.

Shen, X. K., Ma, L. X., Zhong, S. F., Liu, N., Zhang, M., Chen, W. Q., Zhou, Y. L., Li, H. J., Chang, Z. J., Li, X., Bai, G. H., Zhang, H. Y., Tan, F. Q., Ren, Z. L., and Luo, P. G. 2015. Identification and genetic mapping of the putative Thinopyrum intermedium-derived dominant powdery mildew resistance gene PmL962 on wheat chromosome arm 2BS. Theor. Appl. Genet. 128:517-528.

Somers, D. J., Fedak, G., Clarke, J., and Cao, W. 2006. Mapping of FHB resistance QTLs in tetraploid wheat. Genome 49:1586-1593.

Somers, D. J., Isaac, P., and Edwards, K. 2004. A high-density microsatellite consensus map for bread wheat (Triticum aestivum L.). Theor. Appl. Genet. 109:1105-1114.

Song, Q. J., Fickus, E. W., and Cregan, P. B. 2002. Characterization of trinucleotide SSR motifs in wheat. Theor. Appl. Genet. 104:286-293.

Sourdille, P., Singh, S., Cadalen, T., Brown-Guedira, G. L., Gay, G., Qi, L., Gill, B. S., Dufour, P., Murigneux, A., and Bernard, M. 2004. Microsatellitebased deletion bin system for the establishment of genetic-physical map relationships in wheat (Triticum aestivum L.). Funct. Integr. Genomics 4:12-25.

Steiner, B., Lemmens, M., Griesser, M., Scholz, U., Schondelmaier, J., and Buerstmayr, H. 2004. Molecular mapping of resistance to Fusarium head blight in the spring wheat cultivar Frontana. Theor. Appl. Genet. 109:215-224.
Stephenson, P., Bryan, G., Kirby, J., Collins, A., Devos, K., Busso, C., and Gale, M. 1998. Fifty new microsatellite loci for the wheat genetic map. Theor. Appl. Genet. 97:946-949.

Tai, T. H., and Tanksley, S. D. 1990. A rapid and inexpensive method for isolation of total DNA from dehydrated plant tissue. Plant Mol. Biol. Report. 8:297-303.

Tamburic-Ilincic, L., Fedak, G., and Schaafsma, A. W. 2002. Study on deoxynivalenol (DON) and Fusarium head blight (fhb) resistance in a F2 winter wheat population. J. Appl. Genet. 43A:333-340.

Van Ooijen, J. W. 2004. MapQTL 5, Software for the Mapping of Quantitative Trait Loci in Experimental Populations. Kyazma BV, Wageningen, Netherlands.

Van Ooijen, J. W. 2006. JoinMap 4, Software for the Calculation of Genetic Linkage Maps in Experimental Populations. Kyazma BV, Wageningen, Netherlands.

Waldron, B. L., Moreno-Sevilla, B., Anderson, J. A., Stack, R. W., and Frohberg, R. C. 1999. RFLP mapping of QTL for Fusarium head blight resistance in wheat. Crop Sci. 39:805-811.

Wang, S., Basten, C., and Zeng, Z. 2007. Windows QTL cartographer 2.5. Department of Statistics, North Carolina State University, Raleigh, NC.

Xiao, J., Jin, X., Jia, X., Wang, H., Cao, A., Zhao, W., Pei, H., Xue, Z., He, L., Chen, Q., and Wang, X. 2013. Transcriptome-based discovery of pathways and genes related to resistance against Fusarium head blight in wheat landrace Wangshuibai. BMC Genomics 14:197.

Xue, S., Li, G., Jia, H., Xu, F., Lin, F., Tang, M., Wang, Y., An, X., Xu, H., Zhang, L., Kong, Z., and Ma, Z. 2010. Fine mapping Fhb4, a major QTL conditioning resistance to Fusarium infection in bread wheat (Triticum aestivum L.). Theor. Appl. Genet. 121:147-156.

Xue, S., Xu, F., Tang, M., Zhou, Y., Li, G., An, X., Lin, F., Xu, H., Jia, H., Zhang, L., and Kong, Z. 2011. Precise mapping Fhb5, a major QTL conditioning resistance to Fusarium infection in bread wheat (Triticum aestivum L.). Theor. Appl. Genet. 123:1055-1063.

Xue, S., Zhang, Z., Lin, F., Kong, Z., Cao, Y., Li, C., Yi, H., Mei, M., Zhu, H., Wu, J., Xu, H., Zhao, D., Tian, D., Zhang, C., and Ma, Z. 2008. A highdensity intervarietal map of the wheat genome enriched with markers derived from expressed sequence tags. Theor. Appl. Genet. 117:181-189.

Yang, J., Cheng, J., Zou, Y., Xia, Z., and Zhu, J. 2007. QTModel User Manual: Software for Quantitative Trait and Statistical Analysis of Experimental Data. Zhejiang University, China.

Yang, S., Li, X., Chen, W., Liu, T., Zhong, S., Ma, L., Zhang, M., Zhang, H., $\mathrm{Yu}$, D., and Luo, P. 2016. Wheat resistance to Fusarium head blight is associated with changes in photosynthetic parameters. Plant Dis. 100: 847-852.

Yao, J., Ge, Y., Wang, S., Yao, G., Zhou, C., and Qian, C. 1996. Chromosomal location of genes for scab resistance in wheat cultivar Sumai 3. Zuo Wu Xue Bao 23:450-453.

Young, N. D., and Tanksley, S. D. 1989. RFLP analysis of the size of chromosomal segments retained around the Tm-2 locus of tomato during backcross breeding. Theor. Appl. Genet. 77:353-359.

Yu, Y.-J. 1982. Monosomic analysis for scab resistance and yield components in the wheat cultivar Soo-mo 3. Cereal Res. Commun. 10:185-189.

Zhang, J. X., Jin, Y., Rudd, J. C., and Bockelman, H. E. 2008. New Fusarium head blight resistant spring wheat germplasm identified in the USDA National Small Grains Collection. Crop Sci. 48:223-235.

Zhang, L., Chang, Z., Li, X., Zhang, H., Ren, Z., and Luo, P. 2011. Screen and identification of wheat new resistant germplasms to Fusarium head blight. Zhiwu Baohu Xuebao 38:569-570.

Zhang, M., Zhang, R., Yang, J., and Luo, P. 2010. Identification of a new QTL for Fusarium head blight resistance in the wheat genotype "Wang shui-bai". Mol. Biol. Rep. 37:1031-1035.

Zhou, W., Kolb, F. L., Bai, G., Shaner, G., Domier, L. L., and Smith, N. J. 2002. Genetic analysis of scab resistance QTL in wheat with microsatellite and AFLP markers. Genome 45:719-727.

Zhou, W., Kolb, F. L., Yu, J., Bai, G., Boze, L. K., and Domier, L. L. 2004. Molecular characterization of Fusarium head blight resistance in Wangshuibai with simple sequence repeat and amplified fragment length polymorphism markers. Genome 47:1137-1143. 